\title{
BMJ Open Optimal dose of succinylcholine for laryngeal mask airway insertion: systematic review, meta-analysis and metaregression of randomised control trials
}

\author{
Alan Hsi-Wen Liao, ${ }^{1}$ Yu-Cih Lin, ${ }^{2}$ Chyi-Huey Bai, ${ }^{3}$ Chien-Yu Chen ${ }^{1,4,5}$
}

To cite: Liao AH-W, Lin Y-C, Bai C-H, et al. Optimal dose of succinylcholine for laryngeal mask airway insertion: systematic review, meta-analysis and metaregression of randomised control trials. BMJ Open 2017;7:e014274. doi:10.1136/ bmjopen-2016-014274

- Prepublication history and additional material for this paper are available online. To view these files please visit the journal online (http://dx.doi. org/10.1136/bmjopen-2016014274).

Received 14 September 2016 Revised 21 June 2017 Accepted 28 June 2017

\section{CrossMark}

${ }^{1}$ Department of Anesthesiology, Taipei Medical University Hospital, Taipei, Taiwan ${ }^{2}$ School of Nursing, College of Nursing, Taipei Medical University, Taipei, Taiwan

${ }^{3}$ School of Public Health, College of Nutrition and Public Health,

Taipei Medical University, Taipei, Taiwan

${ }^{4}$ Department of Anesthesiology, School of Medicine, College of Medicine, Taipei Medical University, Taipei, Taiwan ${ }^{5}$ Graduate Institute of Humanities in Medicine,

College of Humanities and

Social Sciences, Taipei Medical University, Taipei, Taiwan

Correspondence to

Dr Chien-Yu Chen;

jc2jc@tmu.edu.tw

\section{ABSTRACT}

Objectives To evaluate the optimal dose of succinylcholine for laryngeal mask airway (LMA) insertion and all related morbidities.

Design Systematic review, meta-analysis and metaregression of randomised controlled trials (RCTs). Data source and study eligibility criteria $A$ comprehensive search of RCTs in the PubMed, Embase, the Cochrane Library and the ClinicalTrials.gov registry up to July 2016 and articles that evaluated the use of succinylcholine chloride for LMA insertion were included in the analyses. The relative risk (RR) and the corresponding 95\% Cls were determined.

Intervention Succinylcholine as the coinduction agent and the doses were divided into mini $(\leq 0.3 \mathrm{mg} / \mathrm{kg})$ and low $(0.3-1.0 \mathrm{mg} / \mathrm{kg})$ doses for dose-dependent effect analyses. Primary and secondary outcomes The primary outcome was the first-attempt LMA insertion failure rate. Secondary outcomes included all related adverse events.

Results Data from 10 RCTs comprising 625 participants showed that succinylcholine reduced the first-attempt LMA insertion failure rate (RR, $0.22 ; 95 \% \mathrm{Cl} 0.12$ to 0.43$)$, coughing and gagging (RR, $0.26 ; 95 \% \mathrm{Cl} 0.15$ to 0.45 ) and laryngospasm (RR, $0.14 ; 95 \% \mathrm{Cl} 0.05$ to 0.39 ). The use of succinylcholine did not result in a significant increase of postoperative myalgia (RR, 2.58; $95 \% \mathrm{Cl} 0.79$ to 8.44 ) and did not reduce the risk of postoperative sore throat (RR, 0.76; $95 \% \mathrm{Cl} 0.55$ to 1.03). Subgroup analysis further showed that low-dose succinylcholine reduced the LMA insertion failure rate and its related coughing and gagging when compared with mini dose.

Conclusion The use of succinylcholine compared with none can facilitate LMA insertion and reduce insertionrelated reflexes without significant postoperative myalgia. However, additional prospective studies with a larger sample size are required to fully evaluate the dosedependent effect and complications of succinylcholine for LMA insertion.

\section{INTRODUCTION}

The laryngeal mask airway (LMA) is widely used as an airway maintenance device for both adult and paediatric patients receiving
Strengths and limitations of this study

- This is the first systematic review and meta-analysis to evaluate the possible dose dependent effect of succinylcholine on laryngeal mask airway (LMA) insertion and its associated complications.

- Heterogeneity test, sensitivity analysis, bias assessment and metaregression were conducted.

- Moderate to low heterogeneity were observed for all the outcomes.

- The types of LMA used were not all specified in the primary studies.

- Only two studies were entered for dose-dependent effect analyses with potential type II error.

- The risk of publication bias cannot be totally excluded due to the low number of primary studies included, as well as unpublished negative studies.

general anaesthesia, as well as in the difficult airway algorithm and the emergency room settings. ${ }^{1}$ Despite numerous modifications in the design and insertion techniques, performing a successful smooth first-attempt LMA insertion may still be challenging at times, and according to recent studies, the incidence of reinsertion or reposition remains high. $^{2}{ }^{3}$ Multiple LMA insertion attempts may lead to insertion-related morbidities, including adverse haemodynamic changes, airway trauma and potential dangerous insertion-associated reflexes, such as coughing, gagging and laryngospasm. ${ }^{4-6}$ The role of succinylcholine as a coinduction agent for tracheal intubation has been well established, ${ }^{7}$ as it provides excellent airway relaxation without prolonged apnoea; however, whether it will provide similar condition for LMA insertion is less clear. Recent studies included those with minimal succinylcholine dose for LMA (as low as $\leq 0.3 \mathrm{mg} / \mathrm{kg}$ ) were conducted but had yielded inconclusive 
results thus far. ${ }^{8-11}$ Furthermore, controversy may exists among anaesthesiologists regarding the use of neuromuscular blockers for LMA insertion in clinical practice. As with different training or access to different LMA models, so are with the use of muscle relaxants for LMA insertion. Some would never use them, yet in other circumstances, they may still be considered for LMA insertion. ${ }^{12} 13$ Current evidence regarding the use of succinylcholine for LMA insertion is lacking and further statistical analysis for its use may be warranted. The aim of this study is to verify the optimal dose of succinylcholine for a smooth insertion of LMA with minimal adverse effects through a systematic review as well as a meta-analysis.

We therefore conducted a systematic review and meta-analysis to evaluate the effect of succinylcholine on LMA insertion first-attempt failure rate. In addition, our study also evaluated succinylcholine associated adverse events, such as postoperative sore throat. Other insertion difficulties and insertion-related reflexes as well as the incidence of postoperative morbidities were included as secondary outcomes. Attempt was also made to evaluate the possible dose-dependent effect of succinylcholine for LMA insertion via subgroup and metaregression analyses.

\section{METHODS}

The current systematic review was conducted by following the Preferred Reporting Items for Systematic Reviews and Meta-Analyses guidelines. ${ }^{14}$

\section{Inclusion criteria}

Articles and abstracts were included if they (1) were randomised controlled trials (RCTs), (2) evaluated the use of succinylcholine versus no succinylcholine for LMA insertion, doses were arbitrarily divided into low $(0.3-1 \mathrm{mg} / \mathrm{kg})$ or mini $(\leq 0.3 \mathrm{mg} / \mathrm{kg})$ dose for analyses after considering the study by Naguib et al, ${ }^{10}$ (3) reported any LMA insertion position and complications and (4) listed all succinylcholine-associated adverse events. Control groups included the use of a placebo, such as normal saline, or none.

\section{Exclusion criteria}

RCTs were excluded from our meta-analysis on the basis of the following criteria: (1) head and neck or airway surgeries; (2) none scheduled surgeries; (3) emergency settings and (4) different induction regimens between the intervention and control groups. No age or language limitations were applied in this study.

\section{Search strategy and study selection}

Two reviewers (YCL and CYC) conducted a comprehensive literature search by using various databases, namely PubMed, Embase, the Cochrane central register of controlled trial databases, the ClinicalTrials.gov registry (http:// clinicaltrials.gov), for the period from 1990 up to July 2016. Article selection was limited to human studies, and no language restrictions were applied. An example of search strategy can be found as online supplementary appendix $\mathrm{S} 1$.
The keywords used for the medical subject heading and text searches were laryngeal mask, laryngeal mask airway, LMA, intubating laryngeal mask, LMA Unique, LMA Flexible, LMA ProSeal, LMA Supreme, LMA Fastrach, intubating LMA, ILMA, LMA CTrach, succinylcholine, suxamethonium, scoline, anectine, anekain, celocurine, chlorsuccillin, curacin, curalest, thiocholine, leptosuccin, relaxin, succicholine, succinyl, succinyl asta, succinyl forte, sukolin, sumetw, suxameton, suxametonio cloruro, myoflex, pantolax, kyotensis, laryngospasm, myalgia, sore throat, gagging and coughing. The related citations in the PubMed search tool were used to broaden each search, and the retrieved abstracts, study reports and related citations were all reviewed in detail.

\section{Data extraction}

Two reviewers (YCL and AHWL) independently extracted baseline and outcome data, including the study design, participant data, inclusion and exclusion criteria, type of surgery and anaesthetic techniques, size and type of the used LMA, LMA reinsertion or reposition, insertion-related reflexes and any other complications. A third reviewer (CYC) resolved any inconsistencies between the findings of the two reviewers. To overcome a unit-of-analysis error, for two studies ${ }^{1516}$ we split the 'shared' group into two groups with smaller sample size and include two (reasonably independent) comparisons, in accordance with the recommendations of the Cochrane handbook. (See http://handbook.cochrane.org/chapter_16/16_ 5_4_how_to_include_multiple_groups_from_one_study. $\mathrm{htm}$ for more information.)

\section{Methodological quality appraisal}

Two reviewers (AHWL and YCL) assessed the methodological quality of each study on the basis of the randomisation level, allocation concealment, blinding of the patients and the outcome assessors, length of the follow-up period, reporting of study withdrawals, performance of an intention-to-treat analysis and other possible sources of bias.

\section{Outcomes and statistical and sensitivity analyses}

The primary outcome was the rate of first-attempt LMA insertion failure, as indicated by LMA reinsertion or reposition. The secondary outcomes were insertion difficulties (ie, tight jaws and incomplete mouth opening), unanticipated insertion-related reflexes (ie, coughing or gagging, limb movements and laryngospasm) and postoperative morbidities (ie, postoperative myalgia, postoperative sore throat and hoarseness).

The collected data were entered and analysed using the Review Manager V.5.3 (Cochrane Collaboration, Oxford, UK). If necessary, SD were estimated according to the CI limits or standard errors. The effect sizes of dichotomous and continuous outcomes were reported as the risk ratio (RR) and mean difference, respectively. The precision of the effect sizes was expressed as a $95 \%$ CI. Dichotomous outcomes were represented by arranging the observed counts into fourfold $(2 \times 2)$ tables. The separation of data into different tables or strata represents a subgrouping, 
for example, low dose or mini dose. A pooled risk across the strata and the related CI were provided by MantelHansel method. ${ }^{17}$

In addition, we have also conducted meta-regression to further evaluate the dose-dependent effect of succinylcholine for LMA insertion. Fix or random effect was used according to heterogeneity or statistical assessment of data. For each individual study, the data for metaregression were used by group-level summary count data for the cells of outcomes and the categorised doses (control; low dose, $0.3-1 \mathrm{mg} / \mathrm{kg}$; mini dose, $\leq 0.3 \mathrm{mg} / \mathrm{kg}$ of succinylcholine) as the independent variable. In this case, the measured effect estimates of risk ratio were ORs when we took different designs into account.

We first elected to use the exact logistic regression method for analyses as the fixed-effect estimates is more robust and do not depend on asymptotic results which used the standard maximum likelihood-based estimator. ${ }^{18}$ Especially in the case when the sample size is too small or when some of the cells have no observations. By including fixed effects (group dummies), we controlled for the average differences across groups or unobservable predictors. Due to our study questions, the comparison of doses was focused rather than the generalisability. Furthermore, to model binary outcome variables in which the log odds of the outcome is modelled as a linear combination of the predictors. Log odds were modelled by generalised linear mixed model (for random effect). The random effects are achieved by specifying a correlation matrix; it is assumed that all correlations between individuals in the same cluster are the same ('exchangeable' correlation matrix). SAS V.9.4 software was used for the above analyses. Sensitivity analyses were performed to assess the influence of the study quality on the effect estimates.

We used the Cochrane $\mathrm{Q}$ test and $\mathrm{I}^{2}$ statistics for evaluating the statistical heterogeneity and inconsistency of treatment effects among the selected RCTs. The statistical significance was set at 0.10 for the Cochrane $Q$ tests. The proportion of the total outcome variability that was attributable to the variability among the RCTs was quantified as $\mathrm{I}^{2}$.

\section{RESULTS}

\section{Characteristics of the selected RCTs}

Ten RCTs ${ }^{2} 31516$ 19-24 involving a total of 625 participants met the inclusion criteria. Figure 1 illustrates the RCT screening and selection processes. Our initial search yielded 1466 citations, of which 1213 were excluded after an advanced screening of the titles and abstracts. After reviewing the full text of the remaining 253 reports, only 10 eligible RCTs fit our inclusion criteria and were included in the study. The included RTCs were published between 1997 and 2015, and the reported sample size ranged from 60 to 75 patients. All selected studies were from Asia, except for one. ${ }^{22}$ All trials recruited patients according to the American Society of Anesthesiologists
(ASA) statuses I and II; however, one trial ${ }^{20}$ recruited ASA status I-III patients. The surgeries involved were mainly elective genital urinary and short procedures, and five studies $^{3} 16192123$ did not specify the surgery type. Four studies $^{2} 31924$ specified information on the LMA size and one study $^{2}$ reported the LMA type. Four studies ${ }^{2} 31524$ indicated an experienced anaesthesiologist as the LMA inserter.

Seven studies ${ }^{231622 \text { 25-27 }}$ used propofol as the induction agent of choice; two ${ }^{2324}$ used etomidate, and one ${ }^{20}$ used thiopental. Succinylcholine groups were compared with control groups in all trials. Two studies ${ }^{15} 16$ compared two succinylcholine dose groups. Seven ${ }^{2} 1516$ 20-23 and five $^{315161924}$ studies employed mini $(\leq 0.3 \mathrm{mg} / \mathrm{kg})$ and low $(0.3-1 \mathrm{mg} / \mathrm{kg})$ doses of succinylcholine, respectively, and none used doses $>1 \mathrm{mg} / \mathrm{kg}$. Five studies ${ }^{2} 3162223$ used nitrous oxide $\left(\mathrm{N}_{2} \mathrm{O}\right)$ for maintaining anaesthesia. Nine studies ${ }^{2315-19222^{2}}$ collected data on the number of insertion attempts. Ten studies assessed mouth opening, airway reflexes, patient movements and overall insertion conditions, while eight trials ${ }^{2}{ }^{3} 6^{20-24}$ measured postoperative morbidities. Two studies ${ }^{20} 22$ had mixed data reporting. Length of postoperative follow-up for myalgia was recorded in 6 of the 10 studies. ${ }^{21516202123}$ Additional information on the patient characteristics, anaesthetic techniques, surgical procedures and the interventions adopted is listed in table 1 .

Table 2 provides a summary of the methodological assessment of the included trials. None of the studies specified the allocation generation or concealment methods. Two ${ }^{20}$ and four ${ }^{15} 162123$ studies were double and provider blinded, respectively, whereas the remaining studies ${ }^{319} 22$ did not mention the blinding method. All 10 studies performed a per-protocol analysis. Potential sources of bias and limitations included non-disclosure of the sex percentage, ${ }^{2} 20$ 21 LMA types, ${ }^{3} 1516$ 19-24 LMA size, ${ }^{3} 16$ 20-24 the LMA inserter ${ }^{19-24}$ and surgery type 31619212324 as well as mixed data reporting. ${ }^{20} 22$

\section{First-attempt failure rate}

Nine studies ${ }^{2}{ }^{16} 19-24$ reported the incidence of LMA reposition or reinsertion, and the results indicated that overall succinylcholine use reduced the first-attempt LMA insertion failure rate, with an RR of 0.22 (95\% CI 0.12 to $\left.0.43 ; \mathrm{I}^{2}=57 \% ; \mathrm{p}<0.01\right)$. The RRs were $0.29(95 \%$ CI 0.17 to $\left.0.52 ; \mathrm{I}^{2}=31 \% ; \mathrm{p}<0.01\right)$ and $0.10(95 \%$ CI 0.02 to $0.69 ; \mathrm{I}^{2}=76 \%$; $=0.02$ ) for the mini and low doses of succinylcholine, respectively (figure 2). The absolute first-attempt LMA insertion success rate increased from $43 \%(108 / 250)$ to $88 \%$ and $94 \%$ for the mini and low doses of succinylcholine, respectively. Furthermore, a direct comparison derived from two RCTs indicated that the low dose succinylcholine reduced first time insertion failure rate and offered stronger protection against coughing and gagging than that of the mini dose of succinylcholine (table 3 ). 


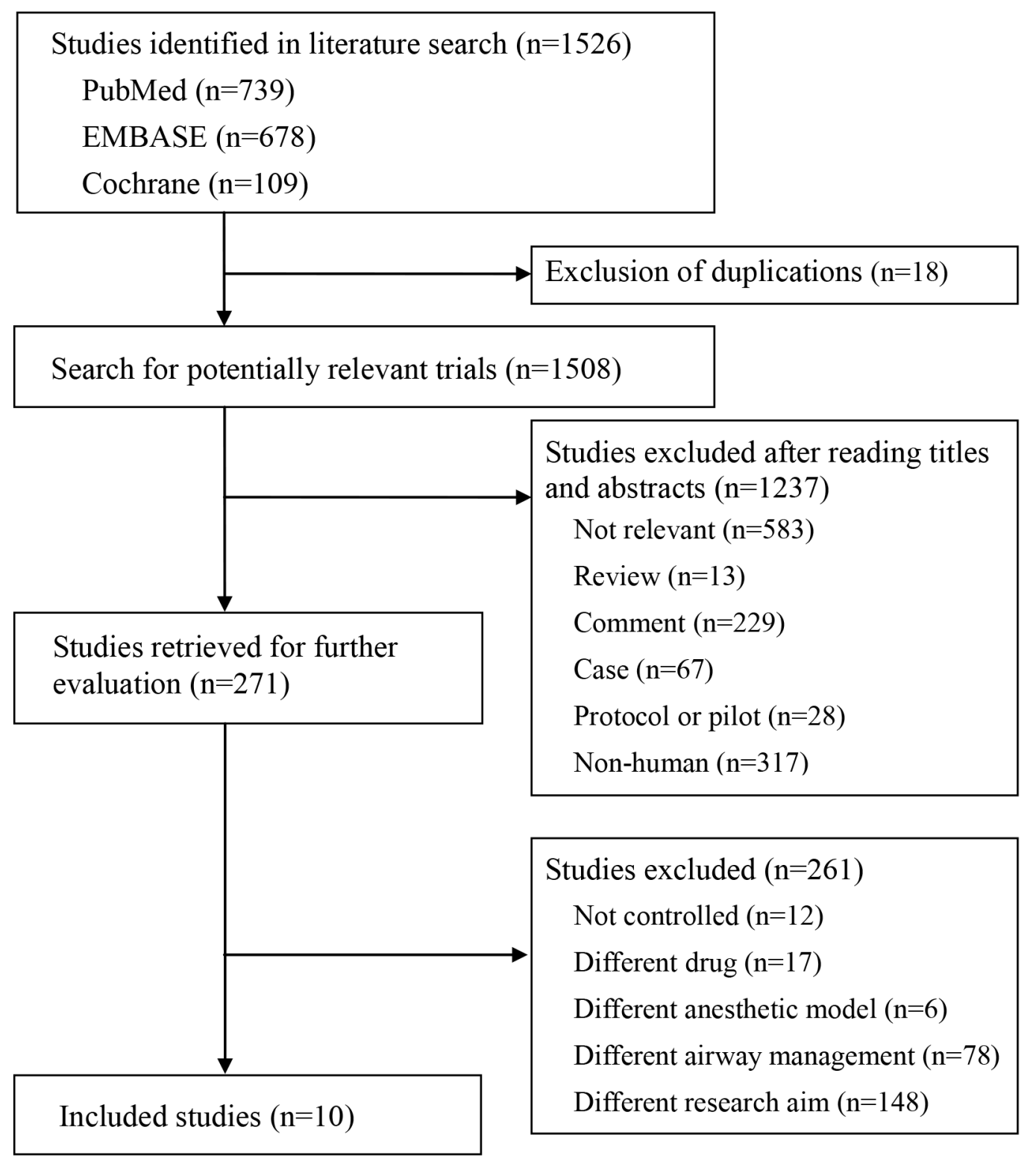

Figure 1 Flowchart of the study selection process.

\section{Incidence of insertion difficulty and unanticipated insertion- related reflexes}

Table 4 provides a summary of all other measured outcomes. The incidence of incomplete mouth opening decreased with the overall use and mini dose of succinylcholine, with RRs of 0.34 (95\% CI 0.17 to $0.67 ; \mathrm{I}^{2}=87 \%$; $\mathrm{p}<0.01)$ and 0.34 (95\% CI 0.14 to $0.81 ; \mathrm{I}^{2}=88 \% ; \mathrm{p}=0.01$ ), respectively. However, the low dose of succinylcholine did not provide significant improvement, with an RR of 0.22 ( $95 \%$ CI 0.01 to $8.46 ; \mathrm{I}^{2}=93 \%$; $\mathrm{p}=0.41$ ).

Compared with the control groups, overall succinylcholine use provided significant protection against the occurrences of coughing and gagging, ${ }^{2} 3151619-23$ limb movements $^{2} 151619-23$ and laryngospasm, ${ }^{2} 151620-23$ with RRs of 0.26 (95\% CI 0.15 to $0.45 ; \mathrm{I}^{2}=65 \%$; $\mathrm{p}<0.01$ ), 0.39 $\left(95 \%\right.$ CI 0.26 to $\left.0.60 ; \mathrm{I}^{2}=46 \% ; \mathrm{p}<0.01\right)$ and $0.17(95 \% \mathrm{CI}$ 0.07 to $0.41 ; \mathrm{I}^{2}=0 \% ; \mathrm{p}<0.01$ ), respectively. The low doses of succinylcholine only offer significant protection against coughing and gagging, with an RR of 0.17 (95\% CI 0.07 to $\left.0.42 ; \mathrm{I}^{2}=0 \% ; \mathrm{p}<0.01\right)$.

\section{Incidence of postoperative morbidities}

Six studies ${ }^{21620212324}$ showed that overall succinylcholine use did not achieve statistical significance for the protection against postoperative sore throat in all groups, with a pooled RR of 0.76 (95\% CI 0.55 to $1.03 ; \mathrm{I}^{2}=0 \%$; $\mathrm{p}=0.08$ ) (figure 3).

Compared with the control groups, postoperative myalgia did not increase with the overall use, mini dose or low dose of succinylcholine, with RRs of 2.58 (95\% CI 0.79 to $8.44 ; \mathrm{I}^{2}=64 \% ; \mathrm{p}=0.12$ ), 2.54 (95\% CI 0.61 to 10.64 ; $\left.\mathrm{I}^{2}=68 \% ; \mathrm{p}=0.20\right)$ and 2.78 (95\% CI 0.51 to $15.05 ; \mathrm{I}^{2}=0 \%$; $\mathrm{p}=0.24$ ), respectively (figure 4 ). The results regarding postoperative myalgia obtained through a direct comparison 


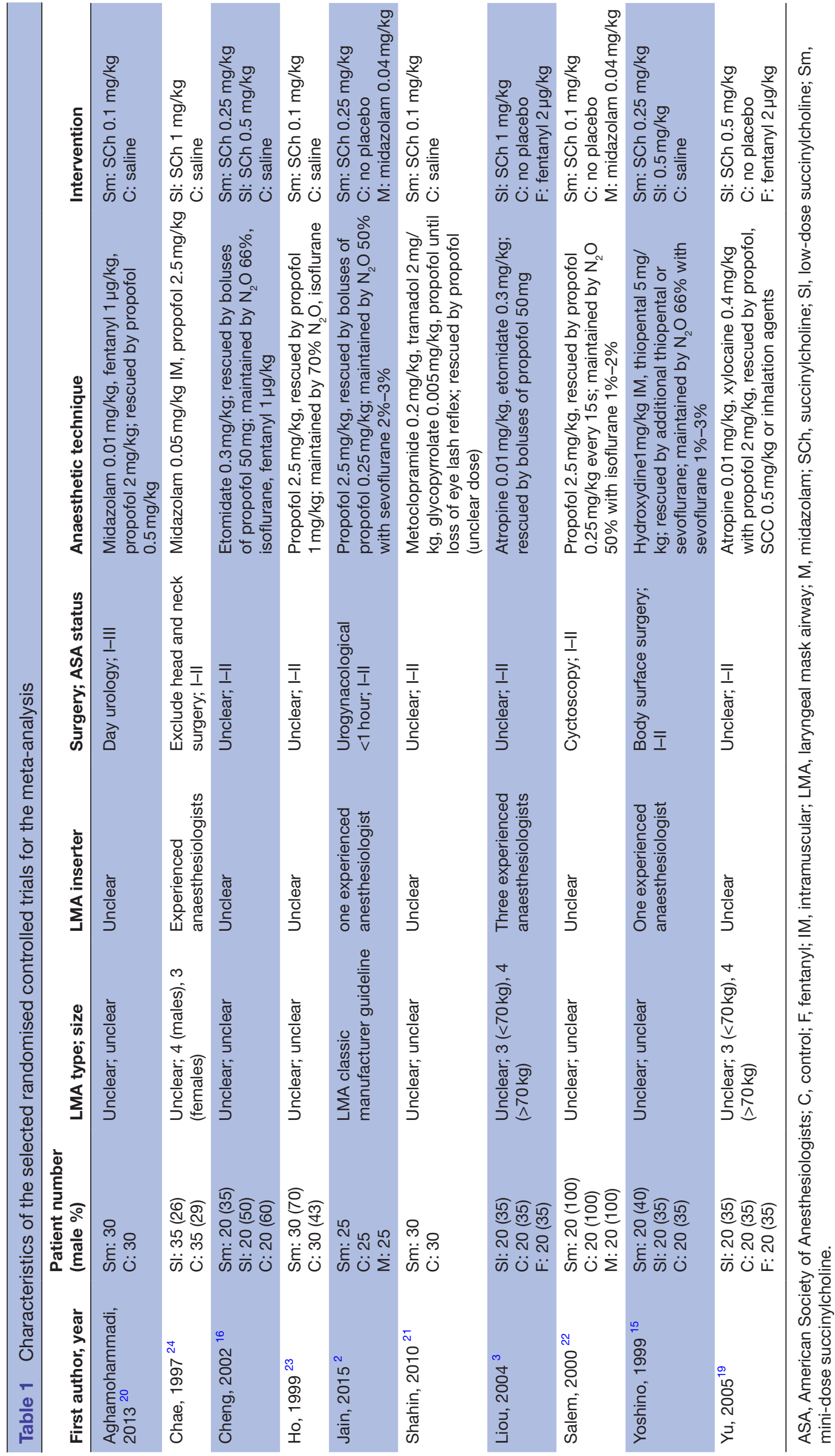


Table 2 Methodological quality assessment of the selected trials

\begin{tabular}{|c|c|c|c|c|c|c|c|}
\hline First author & Country & $\begin{array}{l}\text { Random } \\
\text { sequence } \\
\text { generation }\end{array}$ & $\begin{array}{l}\text { Allocation } \\
\text { concealment }\end{array}$ & Blinding & $\begin{array}{l}\text { Incomplete } \\
\text { outcome } \\
\text { data }\end{array}$ & $\begin{array}{l}\text { Data } \\
\text { analysis }\end{array}$ & Other sources of bias \\
\hline Aghamohammadi $^{20}$ & Iran & $?$ & $?$ & Double & - & PP & $\begin{array}{l}\text { Mixed data of myalgia and } \\
\text { sore throat }\end{array}$ \\
\hline Chae $^{24}$ & Korea & $?$ & $?$ & $?$ & + & PP & No details on sore throat \\
\hline Cheng $^{16}$ & Singapore & $?$ & $?$ & Provider & - & PP & $?$ \\
\hline Jain $^{2}$ & India & $?$ & $?$ & Double & - & PP & $?$ \\
\hline Shahin $^{21}$ & India & $?$ & $?$ & Provider & - & PP & $\begin{array}{l}\text { Significantly different } \\
\text { propofol induction dose }\end{array}$ \\
\hline Liou $^{3}$ & Taiwan & $?$ & $?$ & $?$ & - & PP & $\begin{array}{l}\text { Three patients lost to } \\
\text { follow-up }\end{array}$ \\
\hline $\mathrm{Yu}^{19}$ & Taiwan & $?$ & $?$ & $?$ & - & PP & $?$ \\
\hline
\end{tabular}

PP, per protocol.

between the low and mini doses showed a non-significantly increased RR of 1.47 for low dose (95\% CI 0.32 to $6.84 ; \mathrm{I}^{2}=33 \% ; \mathrm{p}=0.62$ ) (table 3 ). No studies reported any severe complications such as malignant hyperthermia.

\section{Sensitivity analysis}

Table 5 lists potential sources of bias and limitations of the selected RCTs, including (1) using an induction drug other than propofol, ${ }^{315} 16$ (2) administering a propofol induction dose $>2 \mathrm{mg} / \mathrm{kg},{ }^{22-24}$ (3) no specification of the LMA inserter, ${ }^{16-24}$ (4) using $\mathrm{N}_{2} \mathrm{O}$ for maintaining anaesthesia $^{23162223}$ and (5) use of induction opioids. ${ }^{162021} \mathrm{An}$ analysis of the results showed no influence of the potential sources of bias on the primary outcome, with the exception of unspecified LMA inserter. In terms of the secondary outcomes, the incidences of incomplete mouth opening, limb movement, postoperative myalgia and sore throat did not decrease with succinylcholine use when the studies with an unspecified LMA inserter were excluded. The incidence of postoperative myalgia was increased if studies with induction opioids were excluded. By contrast, succinylcholine use showed a protective effect against postoperative sore throat when the studies using induction agents other than propofol and using $\mathrm{N}_{2} \mathrm{O}$ for maintaining anaesthesia were excluded.

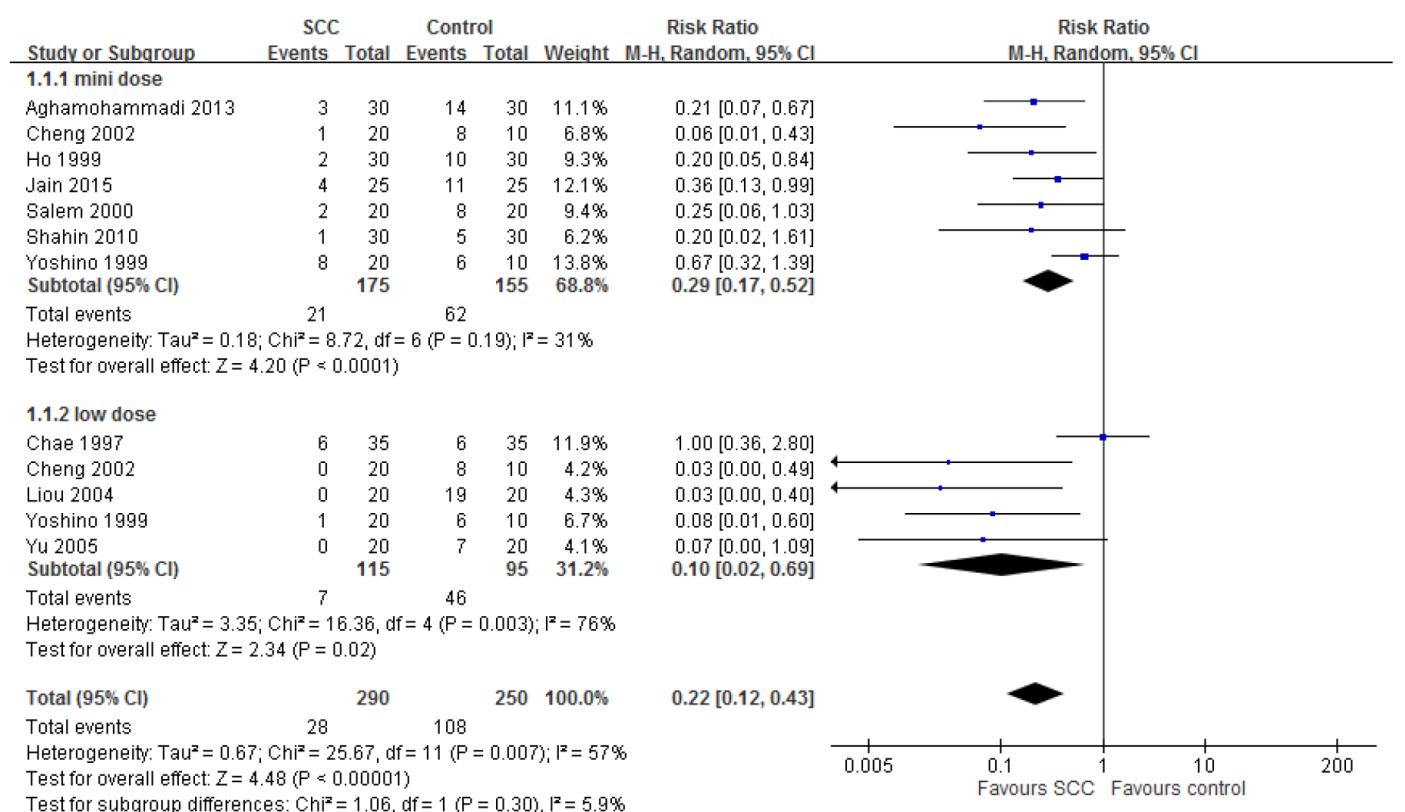

Figure 2 Incidence of LMA reposition or reinsertion. LMA, laryngeal mask airway. 
Table 3 Outcome comparison of the low and mini doses of succinylcholine ${ }^{1516}$

\begin{tabular}{lllll}
\hline Outcome & $\mathbf{R R}$ & $\mathbf{9 5 \%} \mathbf{C l}$ & $\mathbf{I}^{\mathbf{2}}$ & $\mathbf{p}$ Value \\
\hline $\begin{array}{l}\text { Reposition or } \\
\text { reinsertion }\end{array}$ & 0.14 & 0.02 to 0.77 & $0 \%$ & 0.02 \\
$\begin{array}{l}\text { Incomplete mouth } \\
\text { opening }\end{array}$ & 0.80 & 0.52 to 1.25 & $0 \%$ & 0.33 \\
$\begin{array}{l}\text { Coughing and } \\
\text { gagging }\end{array}$ & 0.21 & 0.07 to 0.60 & $0 \%$ & $<0.01$ \\
$\begin{array}{l}\text { Postoperative } \\
\text { myalgia }\end{array}$ & 1.47 & 0.32 to 6.84 & $33 \%$ & 0.62 \\
\hline
\end{tabular}

Number of participants=80; Low dose $=0.3-1 \mathrm{mg} / \mathrm{kg}$; mini dose $\leq 0.3 \mathrm{mg} / \mathrm{kg}$.

\section{Meta regression}

Table 6 presented the meta-regression analyses of the dose-dependent effect of succinylcholine on all measured outcomes. Low and mini doses of succinylcholine are both effective in reducing the first attempt LMA insertion failure rate, with the respective pooled RRs of $0.05(95 \%$ CI 0.02 to $0.10 ; \mathrm{p}<0.05)$ and 0.13 (95\% CI 0.08 to 0.23 ; $\mathrm{p}<0.01)$ for fixed effect model; and 0.07 (95\% CI 0.004 to $1.11 ; \mathrm{p}=0.0596)$ and $0.17(95 \%$ CI 0.10 to $0.31 ; \mathrm{p}<0.0001)$ for random effect model.

\section{DISCUSSION}

This meta-analysis showed that the overall succinylcholine use reduced the incidence of LMA repositioning or reinsertion. Although succinylcholine did not alleviate LMA insertion-related postoperative sore throat, it did not increase the incidence of postoperative myalgia as may be anticipated.
Non-pharmacological strategies for improving the insertion success rate and reducing the associated complications included modifying the LMA design, the degrees of LMA inflation, ${ }^{25}$ prewarming the $\mathrm{LMA}^{26}$ and the development of various insertion techniques. ${ }^{25} 27$ However, a strategy for effortless anaesthetic induction with reduced morbidities is also required as LMA insertion-related complications, including laryngospasm, ${ }^{20}$ airway obstruction ${ }^{28}$ and soft tissue trauma resulting in pneumomediastinum ${ }^{4}$ are still been reported.

In terms of inhalational induction for LMA anaesthesia, desflurane was comparable with sevoflurane in terms of related airway adverse events. ${ }^{29}$ In intravenous induction settings, sevoflurane supplemented with propofol increased the first-attempt success rate ${ }^{30}$; moreover, when compared individually, propofol was preferred for LMA insertion because of its more favourable anaesthetic characteristics and higher patient satisfaction. ${ }^{31}$ Compared with propofol, etomidate had increased excitatory phenomena, such as gagging and myoclonus, ${ }^{3} 1632$ whereas thiopental showed increased laryngospasm, gagging and head movement. ${ }^{33}$ In our study, a sensitivity analysis done aimed at minimising bias generated by the use of non-propofol induction agents had shown that succinylcholine may offer protection against LMA insertion-related postoperative sore throat.

In addition to induction anaesthetics, various coinduction agents, such as benzodiazepines, muscle relaxants, opioids among others, had been proposed to facilitate effortless LMA insertion. Narcotic use with propofol induction is now fairly standard when inserting an LMA, however, only 3 out of the 10 selected studies recorded its use $^{162021}$ and lidocaine was used in one study. ${ }^{19}$ Regarding coadministered muscle relaxant; studies with

\begin{tabular}{|c|c|c|c|c|c|}
\hline Outcome: subgroups & Studies (n) & Patients (n) & Risk ratio $(95 \% \mathrm{Cl})$ & $I^{2}$ & p Value \\
\hline \multicolumn{6}{|c|}{ Incomplete mouth opening } \\
\hline Overall & $8^{2315161921-23}$ & 410 & 0.34 (0.17 to 0.67$)$ & $87 \%$ & $<0.01$ \\
\hline Low dose & $3^{31516}$ & 100 & 0.22 (0.01 to 8.46$)$ & $93 \%$ & 0.41 \\
\hline Mini dose & $8^{2151619-23}$ & 310 & 0.34 (0.14 to 0.81$)$ & $88 \%$ & 0.01 \\
\hline \multicolumn{6}{|l|}{ Cough and gagging } \\
\hline Overall & $9^{23151619-23}$ & 470 & $0.26(0.15$ to 0.45$)$ & $65 \%$ & $<0.01$ \\
\hline Low dose & $4^{3151619}$ & 140 & 0.17 (0.07 to 0.42$)$ & $0 \%$ & $<0.01$ \\
\hline Mini dose & $7^{2315162021}$ & 330 & 0.29 (0.15 to 0.54$)$ & $73 \%$ & $<0.01$ \\
\hline \multicolumn{6}{|l|}{ Limb movements } \\
\hline Overall & $8^{231619-23}$ & 410 & 0.39 (0.26 to 0.60$)$ & $46 \%$ & $<0.01$ \\
\hline Low dose & $3^{31619}$ & 110 & 0.21 (0.04 to 1.24$)$ & $77 \%$ & 0.09 \\
\hline Mini dose & $6^{21620-23}$ & 300 & 0.43 (0.29 to 0.64$)$ & $29 \%$ & $<0.01$ \\
\hline \multicolumn{6}{|l|}{ Laryngospasm } \\
\hline Overall & $7^{231620-23}$ & 390 & 0.17 (0.07 to 0.41$)$ & $0 \%$ & $<0.01$ \\
\hline Low dose & $2^{1516}$ & 60 & 0.32 (0.04 to 2.43 ) & $0 \%$ & 0.27 \\
\hline Mini dose & $7^{231620-23}$ & 330 & 0.14 (0.05 to 0.39$)$ & $0 \%$ & $<0.01$ \\
\hline
\end{tabular}




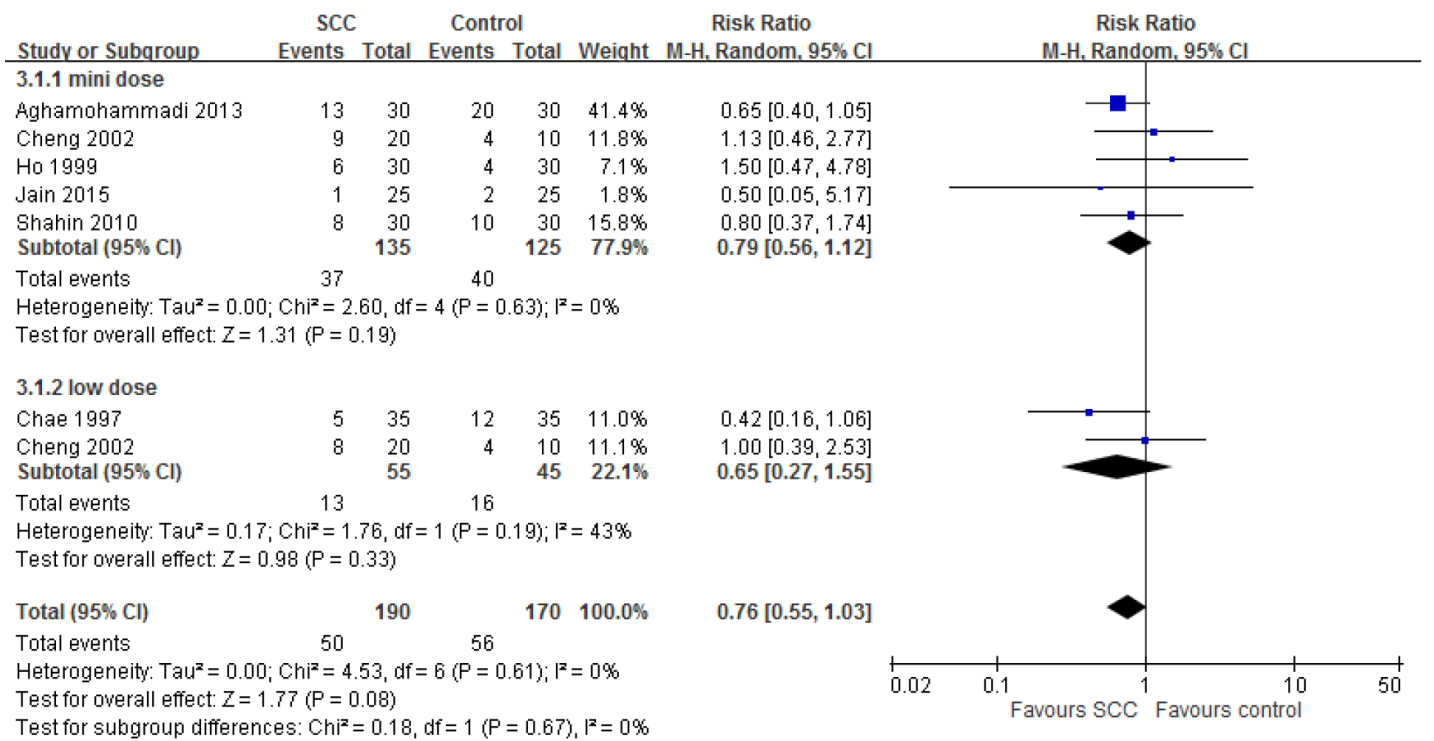

Figure 3 Incidence of postoperative sore throat.

non-depolarising agents showed benefit but at the cost of prolonged apnoea. ${ }^{34-37}$ Yet, a 2004 study reported a full dose of cisatracurium both failed to improve the first-attempt LMA insertion success rate and did not reduce the incidence of pharyngolaryngeal discomfort under mechanical ventilation. ${ }^{38}$ In contrast, findings regarding the potential positive effect of depolarising muscle relaxants on LMA insertion have been more consistent. $^{2815202139}$ Succinylcholine offers rapid, intense yet brief muscle relaxation; thus, so its use may be suitable for LMA anaesthesia.

The notion of using lower doses of succinylcholine for intubation is favoured for minimising undesirable side effects such as a prolonged apnoea time and postoperative myalgia. ${ }^{10}$ Succinylcholine doses of approximately $0.3 \mathrm{mg} /$ $\mathrm{kg}$ have been shown to achieve acceptable intubation conditions without additional side effects relative to the traditional intubation dose of $1 \mathrm{mg} / \mathrm{kg} .{ }^{104041} \mathrm{In}$ our study, we also attempted to explore the possibility of using lower dose of succinylcholine for LMA insertion. Mini doses of $\leq 0.3 \mathrm{mg} / \mathrm{kg}$ were shown to be sufficient in reducing the first attempt LMA insertion failure rate $(70 \%$ risk reduction) with a reduced incidence of coughing, gagging. Low doses $(0.3-1 \mathrm{mg} / \mathrm{kg})$ offered even better success rate (88\% risk reduction).

Postoperative sore throat is a minor but relevant morbidity, as it is ranked as the fifth frequent anaesthetic outcome to have occurred. ${ }^{42}$ Although our result did

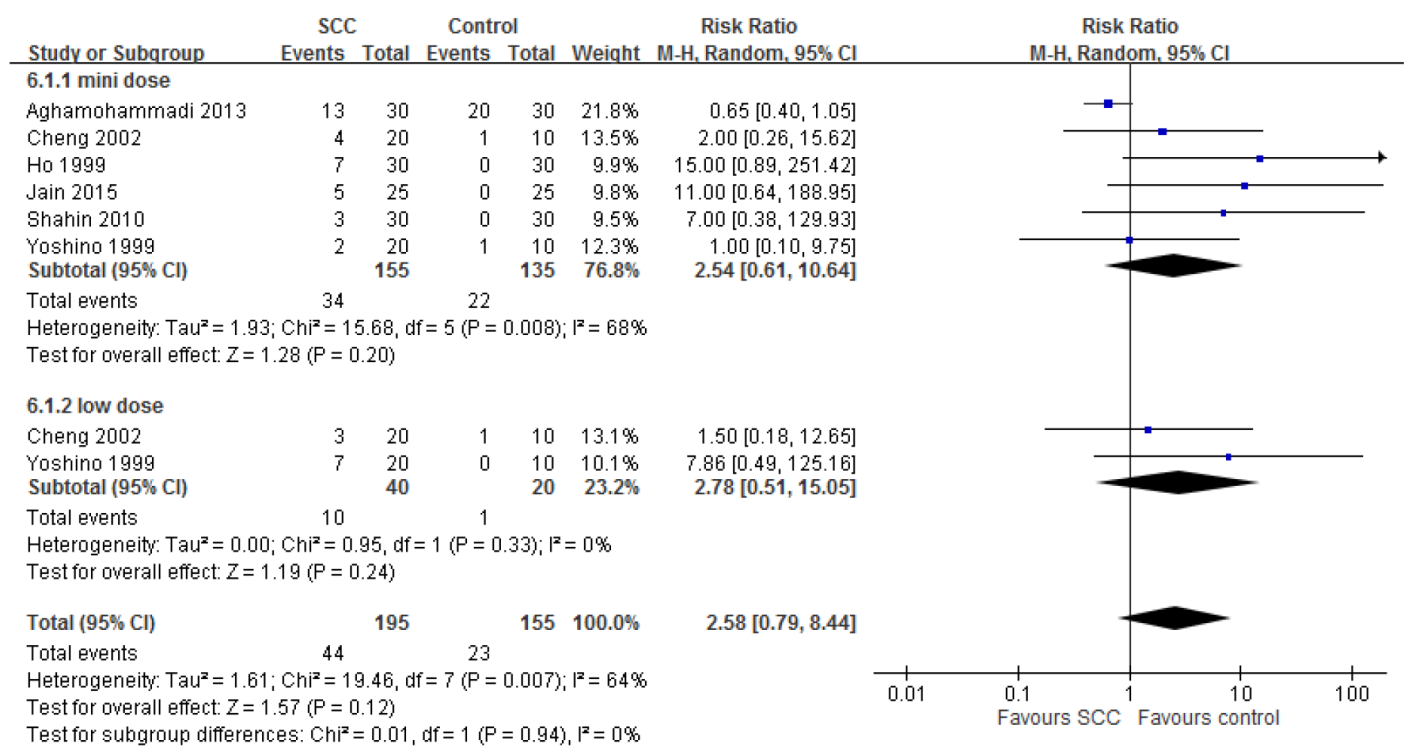

Figure 4 Incidence of postoperative myalgia. 
not show a significant benefit of succinylcholine against sore throat, it nevertheless showed a trend of possible protection (figure 3). Furthermore, $\mathrm{N}_{2} \mathrm{O}$ had been shown to cause an elevated cuff pressure, which can be an important contributing factor for LMA-associated postoperative sore throat. ${ }^{434}$ Our sensitivity analysis revealed a protective effect of the use of succinylcholine against postoperative sore throat when the studies with $\mathrm{N}_{2} \mathrm{O}$ use were excluded. $^{23162223}$

The exact mechanism of succinylcholine-associated postoperative myalgia is unclear, ${ }^{4145-47}$ but it is associated with factors such as male sex, the use of propofol, muscular fitness of the individual, the dose of succinylcholine, intraoperative positioning and early ambulation. ${ }^{48} 49$ Our results failed to demonstrate a significant association between the use of succinylcholine and postoperative myalgia, nevertheless, a positive correlation between the two was observed, especially when induction opioids were excluded as was shown in our sensitivity analysis (table 5).

Difficulties with the control group data in two studies were encountered. In one ${ }^{23}$ the incidence of myalgia in the control group is $100 \%$, and the reason for this observation was not clear from the original script. And in the other, ${ }^{20}$ the mixed data of postoperative myalgia and sore throat in the control group, of which we elected to use the same incidence for control groups of both outcomes.

Sensitivity analysis after excluding unspecified LMA inserter further showed the use of succinylcholine only reduced the incidences of coughing and gagging as well as laryngospasm. This may imply that for seasoned anaesthesiologist, the beneficial effects of succinylcholine may be less relevant for a smooth LMA insertion. This reinforces the notion that operator experience and training are probably the most important considerations for a successful LMA insertion.

In our study, significant heterogeneity existed among the selected RCTs, and it is attributable to several factors. First, different hypnotic and peri-induction agents with varying effects were used in the selected studies. Second, the lack of data on the LMA inserters as well as the sex distribution added to the heterogeneity. Last, the varied clinical practices and non-uniformity of assessment tools and assessors might have further contributed to the heterogeneity among the studies.

This current analysis has several limitations that merit discussion. First, the overall study sample was small, comprising ten RCTs with a total of 625 participants. Second, several selected trials lack essential information, such as the blinding method, randomisation process and the generation and concealment of allocation. Third, lack of details on the type and size of the LMA is a potential limitation, as different design and the generation or size of LMA may all have an impact on the final result. Fourth, methodological problems, such as using various propofol induction doses, further added to the limitations. Fifth, due to the limited information in the current study, we cannot draw conclusion on the dose-dependent effect of succinylcholine. Finally, all selected studies were from 
Table 6 Metaregression of dose-dependent effect on all outcomes

\begin{tabular}{|c|c|c|c|c|c|c|c|c|}
\hline \multirow[b]{2}{*}{$\begin{array}{l}\text { Outcome: } \\
\text { Subgroups }\end{array}$} & \multirow[b]{2}{*}{ Studies (n) } & \multirow[b]{2}{*}{ Patients (n) } & \multicolumn{3}{|c|}{ Fixed effect model* } & \multicolumn{3}{|c|}{ Random effect model† } \\
\hline & & & $\begin{array}{c}\text { Pooled } \\
\text { RR }\end{array}$ & $95 \% \mathrm{Cl}$ & p Value & $\begin{array}{c}\text { Pooled } \\
\text { RR }\end{array}$ & $95 \% \mathrm{Cl}$ & p Value \\
\hline Low dose & $5^{315161924}$ & 210 & 0.04 & 0.02 to 0.10 & $<0.0001$ & 0.07 & $\begin{array}{l}0.004 \text { to } \\
1.11\end{array}$ & 0.0596 \\
\hline Mini dose & $6^{2151621-23}$ & 330 & 0.13 & 0.08 to 0.23 & $<0.0001$ & 0.17 & 0.10 to 0.31 & $<0.0001$ \\
\hline Low dose & $3^{31516}$ & 100 & 0.06 & 0.03 to 0.11 & $<0.0001$ & 0.05 & 0.01 to 0.18 & $<0.0001$ \\
\hline Mini dose & $6^{2151621-23}$ & 270 & 0.20 & 0.12 to 0.33 & $<0.0001$ & 0.13 & 0.04 to 0.39 & 0.0003 \\
\hline \multicolumn{9}{|c|}{ Cough and gagging } \\
\hline Low dose & $3^{31619}$ & 110 & $<0.01$ & NA & $<0.0001$ & NA & NA & NA \\
\hline Mini dose & $7^{215-23}$ & 300 & 0.13 & 0.08 to 0.23 & $<0.0001$ & NA & NA & NA \\
\hline \multicolumn{9}{|c|}{ Limb movements } \\
\hline \multicolumn{9}{|c|}{ Laryngospasm } \\
\hline Low dose & $2^{1516}$ & 60 & 0.03 & $\begin{array}{l}<0.001 \text { to } \\
0.16\end{array}$ & $<0.0001$ & 0.38 & 0.28 to 0.51 & $<0.0001$ \\
\hline Mini dose & $7^{215-182223}$ & 330 & 0.08 & 0.02 to 0.26 & $<0.0001$ & 0.08 & 0.03 to 0.19 & $<0.0001$ \\
\hline \multicolumn{9}{|l|}{ Myalgia } \\
\hline Low dose & $2^{1516}$ & 60 & 0.40 & 0.16 to 0.91 & 0.03 & 3.47 & $\begin{array}{l}0.73 \text { to } \\
16.49\end{array}$ & 0.12 \\
\hline Mini dose & $6^{21516202123}$ & 290 & 1.61 & 0.87 to 3.04 & 0.14 & 1.80 & 0.42 to 7.79 & 0.43 \\
\hline \multicolumn{9}{|l|}{ Sore throat } \\
\hline
\end{tabular}

*Fixed effect model was analysed by using the exact logistic regression.

†Random effect model was analysed by using the general linear mixed model.

LMA, laryngeal mask airway; NA, not applicable; RR, risk ratio.

Asia except for one,${ }^{22}$ thus potential ethnicity-related bias may exist and limits the extrapolation of our results to the other regions.

The strength of this study is that as far as we know, it is the first systematic review and meta-analysis evaluating the both the role of succinylcholine and its possible dose-dependent effect on LMA insertion.

In conclusion, succinylcholine is effective in reducing first attempt LMA insertion failure rate without significant side effects. Although the beneficial effect of mini-dose succinylcholine for LMA insertion and cough reduction is less than low dose, it nevertheless offered clinical benefit compared with none. Additional prospective studies with a larger sample size are required to fully evaluate the dose-dependent effects of succinylcholine for LMA insertion.

Acknowledgements The authors express gratitude to the authors of the primary studies. A special gratitude for the contributions made by Ching-Long Ko, Fai Lam, Ta-Liang Chen and Ka-Wai Tam.

Contributors AHWL, YCL all contributed equally in the study design, data collection, analyses and as well as the drafting the manuscript. CHB helped with the analyses of the data. CYC designed this study, supervised the data collection and revised this article.
Funding Department of Anesthesiology, Taipei Medical University Hospital, Taiwan Competing interests None declared.

Patient consent This meta-analysis did not involve patient directly. No clinical data other than those of the original study were analysed.

Provenance and peer review Not commissioned; externally peer reviewed.

Data sharing statement The statistical code and data set are available from the corresponding authors (CYC) who will provide a permanent, citable and open access home for the data set.

Open Access This is an Open Access article distributed in accordance with the Creative Commons Attribution Non Commercial (CC BY-NC 4.0) license, which permits others to distribute, remix, adapt, build upon this work non-commercially, and license their derivative works on different terms, provided the original work is properly cited and the use is non-commercial. See: http://creativecommons.org/ licenses/by-nc/4.0/

(C) Article author(s) (or their employer(s) unless otherwise stated in the text of the article) 2017. All rights reserved. No commercial use is permitted unless otherwise expressly granted.

\section{REFERENCES}

1. Pollack CV. The laryngeal mask airway: a comprehensive review for the emergency physician. J Emerg Med 2001;20:53-66.

2. Jain N, Parikh GP. Midazolam or mini-dose succinylcholine as co-induction agent to aid laryngeal mask airway insertion during propofol anaesthesia. Int J Res Med 2015;4:62-8. 
3. Liou CM, Hung WT, Chen CC, et al. Improving the success rate of laryngeal mask airway insertion during etomidate induction by using fentanyl or succinylcholine. Acta Anaesthesiol Taiwan 2004:42:209-13.

4. Atalay YO, Kaya C, Aktas S, et al. A complication of the laryngeal mask airway: pharyngolaryngeal rupture and pneumomediastinum. Eur J Anaesthesiol 2015;32:439-40.

5. Ramachandran SK, Mathis MR, Tremper KK, et al. Predictors and clinical outcomes from failed laryngeal mask Airway unique: a study of 15,795 patients. Anesthesiology 2012;116:1217-26.

6. Stiff G, Old S, Bapat P, et al. Laryngeal mask airway and pulmonary edema. Anesthesiology 1993;79:184-5.

7. Fleming NW, Chung F, Glass PS, et al. Comparison of the intubation conditions provided by rapacuronium (ORG 9487) or succinylcholine in humans during anesthesia with fentanyl and propofol. Anesthesiology 1999;91:1311-7.

8. Stewart KG, Hopkins PM, Dean SG. Comparison of high and low doses of suxamethonium. Anaesthesia 1991;46:833-6.

9. Wong SF, Chung F. Succinylcholine-associated postoperative myalgia. Anaesthesia 2000;55:144-52.

10. Naguib M, Samarkandi A, Riad W, et al. Optimal dose of succinylcholine revisited. Anesthesiology 2003;99:1045-9.

11. Kopman AF, Zhaku B, Lai KS. The 'intubating dose' of succinylcholine: the effect of decreasing doses on recovery time. Anesthesiology 2003;99:1050-4.

12. Monem A, Khan F. Laryngeal mask airway insertion anaesthesia and insertion techniques. JPMA 2007 http://jpma.org.pk/full_article_text. php?article_id=1264.

13. Fujiwara A, Komasawa N, Nishihara I, et al. Muscle relaxant effects on insertion efficacy of the laryngeal mask ProSeal in anesthetized patients: a prospective randomized controlled trial. $J$ Anesth 2015;29:580-4.

14. Liberati A, Altman DG, Tetzlaff J, et al. The PRISMA statement for reporting systematic reviews and meta-analyses of studies that evaluate healthcare interventions: explanation and elaboration. BMJ 2009;339:b2700.

15. Yoshino A, Hashimoto Y, Hirashima J, et al. Low-dose succinylcholine facilitates laryngeal mask airway insertion during thiopental anaesthesia. Br J Anaesth 1999;83:279-83.

16. Cheng C, Raman S, Ridgway T, et al. Use of low-dose suxamethonium to facilitate laryngeal mask insertion under etomidate anaesthesia. Internet J Anesthesiol 2002;6:2.

17. Breslow N. Covariance analysis of censored survival data. Biometrics 1974;30:89-99.

18. Martin DO, Austin $\mathrm{H}$. Exact estimates for a rate ratio. Epidemiology 1996;7:29-33.

19. Yc Y, Hung WT, Liou CM, et al. Improving laryngeal mask airway insertion success by using fentanyl or succinylcholine as adjunct in propofol induction. The Chung Shan Medical Journal 2005;16:17-22.

20. Aghamohammadi D, Eydi M, Hosseinzadeh $\mathrm{H}$, et al. Assessment of mini-dose Succinylcholine effect on facilitating laryngeal mask airway insertion. J Cardiovasc Thorac Res 2013;5:17-21.

21. Shahin NJ, Vinay S, Habib SK. The effect of mini-dose suxamethonium to facilitate laryngeal mask airway insertion under propofol anaesthesia. Rawal Medical Journal 2010;35:2-5.

22. Salem WT. A comparison of midazolam and mini-dose succinylcholine to aid laryngeal mask airway insertion during propofol anaesthesia. J Egypt Natl Canc Inst 2000;12:65-9.

23. Ho KM, Chui PT. The use of mini-dose suxamethonium to facilitate the insertion of a laryngeal mask airway. Anaesthesia 1999;54:686-9.

24. Chae YK, Lee YS, Jo DH, et al. Insertion of laryngeal mask airway with Succinylcholine Administration. Korean $J$ Anesthesiol 1997;32:919-23.

25. Ghai B, Makkar JK, Bhardwaj N, et al. Laryngeal mask airway insertion in children: comparison between rotational, lateral and standard technique. Paediatr Anaesth 2008;18:308-12.

26. Komasawa N, Nishihara I, Tatsumi S, et al. Prewarming of the i-gel facilitates successful insertion and ventilation efficacy with muscle relaxation: a randomized study. J Clin Anesth 2014;26:663-7.
27. Choo CY, Koay CK, Yoong CS. A randomised controlled trial comparing two insertion techniques for the laryngeal mask airway Flexibe in patients undergoing dental surgery. Anaesthesia 2012;67:986-90.

28. Lalwani K, Richins S, Aliason I, et al. The laryngeal mask airway for pediatric adenotonsillectomy: predictors of failure and complications. Int J Pediatr Otorhinolaryngol 2013;77:25-8.

29. Stevanovic A, Rossaint R, Fritz HG, et al. Airway reactions and emergence times in general laryngeal mask airway anaesthesia: a meta-analysis. Eur J Anaesthesiol 2015;32:106-16.

30. Siddik-Sayyid SM, Aouad MT, Taha SK, et al. A comparison of sevoflurane-propofol versus sevoflurane or propofol for laryngeal mask airway insertion in adults. Anesth Analg 2005;100:1204-9.

31. Joo HS, Perks WJ. Sevoflurane versus propofol for anesthetic induction: a meta-analysis. Anesth Analg 2000;91:213-9.

32. Uzun S, Gözaçan A, Canbay O, et al. Remifentanil and etomidate for laryngeal mask airway insertion. J Int Med Res 2007;35:878-85.

33. Scanlon P, Carey M, Power M, et al. Patient response to laryngeal mask insertion after induction of anaesthesia with propofol or thiopentone. Can J Anaesth 1993;40:816-8.

34. Cheam EW, Chui PT. Randomised double-blind comparison of fentanyl, mivacurium or placebo to facilitate laryngeal mask airway insertion. Anaesthesia 2000;55:323-6.

35. Chui PT, Cheam EW. The use of low-dose mivacurium to facilitate insertion of the laryngeal mask airway. Anaesthesia 1998;53:491-5.

36. Koh KF, Chen FG, Cheong KF, et al. Laryngeal mask insertion using thiopental and low dose atracurium: a comparison with propofol. Can $J$ Anaesth 1999;46:670-4.

37. Fujiwara A, Komasawa N, Nishihara I, et al. Muscle relaxant effects on insertion efficacy of the laryngeal mask ProSeal in anesthetized patients: a prospective randomized controlled trial. J Anesth 2015;29:580-4.

38. Hemmerling TM, Beaulieu P, Jacobi KE, et al. Neuromuscular blockade does not change the incidence or severity of pharyngolaryngeal discomfort after LMA anesthesia. Can J Anaesth 2004;51:728-32.

39. Monem A, Chohan U. Comparison of low dose succinylcholine with low dose atracurium to evaluate LMA insertion during thiopentone induction. $J$ Anaesthesiol Clin Pharmacol 2004;20:30-44.

40. Kopman AF, Klewicka MM, Neuman GG. An alternate method for estimating the dose-response relationships of neuromuscular blocking drugs. Anesth Analg 2000;90:1191-7.

41. Nimmo SM, McCann N, Broome IJ, et al. Effectiveness and sequelae of very low-dose suxamethonium for nasal intubation. Br J Anaesth 1995;74:31-4.

42. Macario $\mathrm{A}$, Weinger $\mathrm{M}$, Truong $\mathrm{P}$, et al. Which clinical anesthesia outcomes are both common and important to avoid? the perspective of a panel of expert anesthesiologists. Anesth Analg 1999;88:1085-91.

43. Ouellette RG. The effect of nitrous oxide on laryngeal mask cuff pressure. J Am Assoc Nurse Anesth 2000;68:411-4.

44. Burgard G, Möllhoff T, Prien T. The effect of laryngeal mask cuff pressure on postoperative sore throat incidence. J Clin Anesth 1996:8:198-201.

45. Schreiber JU, Lysakowski C, Fuchs-Buder T, et al. Prevention of succinylcholine-induced fasciculation and myalgia: a meta-analysis of randomized trials. Anesthesiology 2005;103:877-84.

46. Nigrovic V, Wierda JM. Post-succinylcholine muscle pain and smoking. Can J Anaesth 1994;41:453-4.

47. Wong SF, Chung F. Succinylcholine-associated postoperative myalgia. Anaesthesia 2000;55:144-52.

48. Kararmaz A, Kaya S, Turhanoglu S, et al. Effects of high-dose propofol on succinylcholine-induced fasciculations and myalgia. Acta Anaesthesiol Scand 2003;47:180-4.

49. Akhavan A, Gainsburg DM, Stock JA. Complications associated with patient positioning in urologic surgery. Urology 2010;76:1309-16. 